\title{
Finite Element Analysis of Timoshenko Beam Using Energy Separation Principle
}

\author{
M. E. Onyia ${ }^{1}$ and E. O. Rowland-Lato ${ }^{2}$ \\ ${ }^{1}$ Department of Civil Engineering, University of Nigeria, Nsukka. Nigeria. \\ ${ }^{2}$ Department of Civil Engineering, University of Port Harcourt, Choba. Nigeria.
}

ORCID: 0000-0002-0956-0077

\begin{abstract}
This paper develops a Timoshenko beam finite element that is free from shear locking by successfully decoupling bending and shear curvatures using energy separation principle. The results obtained using this element are seen to be in very good agreement with classical beam theories for combined bending and shear deformation. The developed beam element can readily be incorporated into finite element programs and used to solve beam and frame problems of various configurations, loading and support conditions. It is concluded that the effect of shear deformation on deflection of beams is significant for span-to-depth ratio less than 10 and should therefore be accounted for in the design of such beams.
\end{abstract}

Keywords: Finite element, Shear-locking, Timoshenko beam

\subsection{INTRODUCTION}

Beams represent the most common structural component found in civil and mechanical engineering structures. They are extensively studied because of their ubiquity. Beams may be used as isolated structures, but can also be combined to form framework structures, exemplified in high-rise buildings, frames and tower construction. Individual beam components of a framework are called members, which are connected at joints, and are subjected to loads at joints and between joints.

Finite element solution of beams has predominantly been based on the Euler-Bernoulli beam theory (EBT), which neglects the existence of through-thickness shear strains variation to justify the plane section hypothesis. On the other hand, this theory is not applicable for moderately short and thick beams, laminate composite beams, and functionally graded beams and plates which find wide application in modern industrial designs. With the increase in the thickness of the beam, the shear deformation effect becomes significant and the error of response increases if Euler-Bernoulli theory is used, [Antes, 2003]. Consequently, the effect of shear transformation is formulated in Timoshenko beam theory (TBT).

The Timoshenko beam theory, a first-order shear deformable beam theory, by considering the relaxation of plane sections and normality assumptions, has successfully accommodated the shear effects by incorporating in its governing equation a constant through-thickness shear strain variation. However the finite elements derived from the TBT have tended to be unsatisfactory as they exhibit shear locking due to a number of possible causes. It has been observed that the use of linear shape functions to represent transverse deflection, w, and cross- sectional rotation, $\theta$, in TBT leads to an overly stiff element. The net displacement will therefore be much less than that observed in the actual structure. Such behavior is known as shear locking, (Reddy, 1997). The shear locking phenomenon results when the stiffness of the structure is significantly over-predicted (i.e displacement is underpredicted) due to the inconsistency of the assumed interpolation function. Carpenters (1986) credited the coupling between bending and shear rotation in the Timoshenko beam equations as the cause of shear locking and suggested that these be decoupled through the use of appropriate strain fields. Prathap (1982, 1987) attributed shear locking to the choice of interpolation functions used for the displacement fields, which impose spurious constraints that occur because the strains developed from the displacement approximation are inconsistent. He recommended that the interpolation function for the shear deformation should different from that for flexural deformation. Edem (2006) proposed an exact relationship between bending and shear rotation. He made use of bending and shear rotation interdependent shape function which allows straightforward interpolation of bending curvature from the usual cubic interpolation polynomials and a proposed shear curvature using linear interpolation polynomials.. The drawback is the level of accuracy associated with the use of linear interpolation polynomials for shear curvature when dealing with eigenvalue problems.

In this paper, an analytical bending-shear rotation interaction factor is derived, the introduction of which enables the decoupling of the bending and shear curvatures in Timoshenko beam governing equations. The factor is derived from bending and shear strain energy consideration in a loaded beam. The formulation allows for the approximation of the decoupled displacement variables, namely the transverse displacement and shear rotation, using cubic and quadratic polynomials respectively. This leads to the emergence of a locking-free Timoshenko beam stiffness matrix and consistent load vector in the finite element solution. 


\subsection{FORMULATION OF TIMOSHENKO BEAM FINITE ELEMENT}

Consider a Timoshenko beam element made of an isotropic homogenous linear elastic material of Young's modulus $E$, shear modulus $G$, Poisson's ratio $v$, and moment of inertia, I. (Fig. 1)

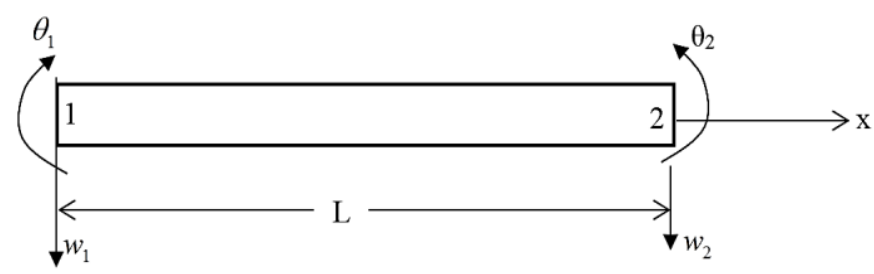

Fig.1. Beam Element

The beam deflection $\mathrm{w}$ is divided into two components: that due to the flexure, $\mathrm{w}_{\mathrm{b}}$ and that due to transverse shea, $\mathrm{r}_{\mathrm{s}}$.

\subsection{Interpolation functions for Flexural Deformation $\left(w_{b}\right)$}

Using Hermite cubic polynomial to approximate the flexural deformation, $\mathrm{w}_{\mathrm{b}}(\mathrm{x})$ :

$w_{b}(x)=a_{1}+a_{2} x+a_{3} x^{2}+a_{4} x^{3}$

The slope, $\theta_{b}=\frac{d w_{b}}{d x}=a_{2}+2 a_{3} x+3 a_{4} x^{2}$

The generalized nodal displacements for the Bernoulli beam are defined as $w_{b}$ and $\theta_{b}$.

Using Equations (1) and (2):

$w_{b}(x=0)=w_{b 1}=a_{1}$

$w_{b}(x=L)=w_{b 2}=a_{1}+a_{2} L+a_{3} L^{2}+a_{4} L^{3}$

$\theta_{b}(x=0)=\theta_{b 1}=a_{2}$

$\theta_{b}(x=L)=\theta_{b 2}=a_{2}+2 a_{3} L+3 a_{4} L^{2}$

Putting Equations (3) in matrix form:

$$
\left\{\begin{array}{l}
w_{b 1} \\
\theta_{b 1} \\
w_{b 2} \\
\theta_{b 2}
\end{array}\right\}=\left[\begin{array}{cccc}
1 & 0 & 0 & 0 \\
0 & 1 & 0 & 0 \\
1 & L & L^{2} & L^{3} \\
0 & 1 & 2 L & 3 L^{2}
\end{array}\right]\left\{\begin{array}{l}
a_{1} \\
a_{2} \\
a_{3} \\
a_{4}
\end{array}\right\}
$$

Solving by matrix inversion:

$$
\left\{\begin{array}{l}
a_{1} \\
a_{2} \\
a_{3} \\
a_{4}
\end{array}\right\}=\left[\begin{array}{lllc}
1 & 0 & 0 & 0 \\
0 & 1 & 0 & 0 \\
-3 / L^{2} & -2 / L & 3 / L^{2} & -1 / L \\
2 / L^{3} & 1 / L^{2} & -2 / L^{3} & 1 / L^{2}
\end{array}\right]\left\{\begin{array}{l}
w_{b 1} \\
\theta_{b 1} \\
w_{b 2} \\
\theta_{b 2}
\end{array}\right\}
$$

From Equation (1):

$w_{b}(x)=a_{1}+a_{2} x+a_{3} x^{2}+a_{4} x^{3}$

Substituting for $\mathrm{a}_{1}, \mathrm{a}_{2}, \mathrm{a}_{3}, \mathrm{a}_{4}$ from Equations (5):

$w_{b}(x)=\sum_{i=1}^{4} \varphi_{i}(x)\left\{u_{i}\right\}$

where $\varphi_{i}$ 's are given as

$$
\begin{gathered}
\varphi_{i}=\frac{L^{3}-3 L x^{2}+2 x^{3}}{L^{3}}, \quad \varphi_{2}=\frac{x L^{3}-2 L^{2} x^{2}+L x^{3}}{L^{3}}, \\
\varphi_{3}=\frac{3 L x^{2}-2 x^{3}}{L^{3}}, \quad \varphi_{4}=\frac{x^{3}-L x^{2}}{L^{2}}
\end{gathered}
$$

and $\left\{u_{i}\right\}$ denotes the column displacement vector $\left\{w_{b 1}, \theta_{b 1}, w_{b 2}, \theta_{b 2}\right\}^{T}$

\subsection{Interpolation functions for Shear Deformation $\left(\mathrm{w}_{\mathrm{s}}\right)$}

The shear beam displacement, $\mathrm{w}_{\mathrm{s}}$, is approximated using a quadratic polynomial:

$w_{s}(x)=1+b_{1}+b_{2} x+b_{3} x^{2}$

The slope, $\theta_{s}=\frac{d w_{s}}{d x}=1+b_{2}+2 b_{3} x$

The generalized nodal displacements for the shear beam are defined by $w_{s}$ and $\theta_{s}$.

Using Equation (8):

$$
\begin{aligned}
& w_{s}(x=0)=w_{s 1}=1+b_{1} \\
& w_{s}(x=L)=w_{s 2}=1+b_{1}+b_{2} L+b_{3} L^{2} \\
& \theta_{s}(x=0)=\theta_{s 1}=1+b_{2} \\
& \theta_{s}(x=L)=\theta_{s 2}=1+b_{2}+2 b_{3} L
\end{aligned}
$$

In matrix form:

$$
\left\{\begin{array}{l}
w_{s 1} \\
\theta_{s 1} \\
w_{s 2} \\
\theta_{s 2}
\end{array}\right\}=\left[\begin{array}{cccc}
1 & 1 & 0 & 0 \\
1 & 0 & 1 & 0 \\
1 & 1 & L & L^{2} \\
1 & 0 & 1 & 2 L
\end{array}\right]\left\{\begin{array}{l}
1 \\
b_{1} \\
b_{2} \\
b_{3}
\end{array}\right\}
$$

Solving by matrix inversion: 
International Journal of Engineering Research and Technology. ISSN 0974-3154, Volume 13, Number 1 (2020), pp. 28-35

(C) International Research Publication House. https://dx.doi.org/10.37624/IJERT/13.1.2020.28-35

$\{b\}=\left\{\begin{array}{l}1 \\ b_{1} \\ b_{2} \\ b_{2}\end{array}\right\}=\left[\begin{array}{cccc}1 / L & 1 / 2 & -1 / L & 1 / 2 \\ (L-1) / L & -1 / 2 & 1 / L & -1 / 2 \\ -1 / L & 1 / 2 & 1 / L & -1 / 2 \\ 0 & -1 / 2 L & 0 & 1 / 2 L\end{array}\right]\left\{\begin{array}{l}w_{s 1} \\ \theta_{s 1} \\ w_{s 2} \\ \theta_{s 2}\end{array}\right\}(10)$

From Equation (8), $w_{s}(x)=1+b_{1}+b_{2} x+b_{3} x^{2}$

Substituting for $b_{1}, b_{2}, b_{3}$ from Equation (10):

$w_{s}(x)=\sum_{i=1}^{4} \eta_{i}(x)\left(u_{i}\right)$

and $\eta_{i}$ are given as

$$
\begin{aligned}
& \eta_{1}=1-\frac{x}{L}, \eta_{2}=\frac{L}{2}\left(\frac{x}{L}-\left(\frac{x}{L}\right)^{2}\right), \\
& \eta_{3}=\frac{x}{L} \text { and } \eta_{4}=-\frac{L}{2}\left(\frac{x}{L}-\left(\frac{x}{L}\right)^{2}\right)
\end{aligned}
$$

and $\left\{u_{i}\right\}$ denotes the column displacement vectors $\left\{w_{s 1}, \theta_{s 1}, w_{s 2}, \theta_{s 2}\right\}^{T}$

\subsection{Formulation of Bending-Shear Interaction Factor}

To ensure continuous interaction between the bending and shear components as a function and avoid the use of partial derivatives, the following relationship for the total cross sectional rotation $\theta$ is proposed as (Onyia and Rowland-lato, 2018):

$\theta(x)=\beta \theta_{b}(x)+(1-\beta) \theta_{s}(x)$

$\theta(x)$ is the total cross-sectional rotation of the beam

$\theta_{b}(x)$ is the cross-sectional rotation of the Euler-Bernoulli beam

$\theta_{s}(x)$ is the cross-sectional rotation of the shear beam

$\beta$ is the bending-shear interaction factor and is expressed as the ratio of bending strain energy $U_{b}$ to total strain energy of a simply-supported beam under load.

That is:

$\beta=\frac{U_{b}}{U_{b}+U_{s}}=\frac{1}{1+\Phi}$

where $\Phi=\frac{U_{s}}{U_{b}}$

$U_{s}=$ strain energy due to shear deformation
The integral expression for bending strain energy is given by the familiar expression:

$U_{b}=\int_{0}^{L} \frac{(M(x))^{2}}{2 E I} d x$

where $\mathrm{E}$ is the elastic modulus of the beam material.

$$
\begin{aligned}
& \mathrm{I}=\text { moment of inertia of the beam section. } \\
& \mathrm{M}(\mathrm{x})=\text { bending moment }
\end{aligned}
$$

Consider a simply supported beam with a point load $\mathrm{P}$ at midspan.

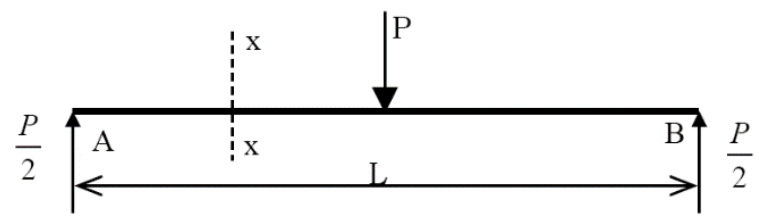

Fig.2. A simply supported beam under a point load $\mathrm{P}$ at the center

The bending moment at a section, distance $\mathrm{x}$ from a support, is given by:

$$
\begin{aligned}
& M(x)=\frac{P x}{2}, \mathrm{x}<\mathrm{L} / 2 \\
& \text { and } M(x)=\frac{P x}{2}-P\left(x-\frac{L}{2}\right), \mathrm{x}>\mathrm{L} / 2
\end{aligned}
$$

Since the maximum bending moment occurs at midspan $(\mathrm{x}=\mathrm{L} / 2)$,

$M(x)=\frac{P x}{2}$

Substituting for $M(x)$ in Equation (16) and performing the integration gives

$\therefore U_{b}=\frac{P^{2} L^{3}}{96 E I}$

The shear force at any section, distance $\mathrm{x}$ from a support, is:

$Q(x)=\frac{P}{2}$

The integral expression for shear strain energy is given by the familiar expression

$U_{s}=\int_{0}^{L} \frac{(Q(x))^{2}}{2 k A G} d x$

Substituting for $Q(x)$ in Equation (19) gives the shear strain energy as: 
$U_{s}=\frac{P^{2} L}{8 k A G}$

$\therefore \Phi=\frac{U_{s}}{U_{b}}=\frac{12 E I}{L^{2} k A G}$

where $E=$ Young's modulus

$$
\begin{aligned}
& G=\text { shear modulus } \\
& A=\text { cross-sectional area } \\
& \mathrm{k}=\begin{array}{l}
\text { shear coefficient depending on the shape of } \\
\text { cross-section } .
\end{array}
\end{aligned}
$$

Edem (2006) proposed that the bending-shear interaction factor, $\beta$, be based on the value of $\Phi$ for midspan point load, i.e. Equation (21).

\subsection{Beam Element Stiffness Matrix}

The relationship between elastic moment and rotation in beam has the form:

$\theta(x)=\int \frac{M}{E I} d x$

Or $M=E I \dot{\theta}(x)$

But the relationship for the total cross sectional rotation $\theta$ has been proposed in Equation (13) as:

$\theta(x)=\beta \theta_{b}+(1-\beta) \theta_{s}(x)$

Substituting for $\theta(\mathrm{x})$ in Equation (22):

$$
\begin{aligned}
M & =E I\left(\beta \dot{\theta}_{b}+(1-\beta) \dot{\theta}_{s}\right) \\
& =\mathrm{M}_{\mathrm{b}}+\mathrm{M}_{\mathrm{s}}
\end{aligned}
$$

where $M_{b}$ and $M_{s}$ are different moments arising from the distinct nature of the resulting bending and shear curvatures respectively.

The expression for strain energy in the proposed beam element is obtained by integrating the expression for strain energy per unit length of the beam plus that due to the distributed load.

The total energy in the unified beam element loaded by distributed normal load, $\mathrm{q}$ is given by:

$$
\begin{aligned}
U\left(\theta_{b}, \theta_{s}, q\right) & =\int \frac{M_{b}^{2}}{2 E I} d x+\int \frac{M_{s}^{2}}{2 E I} d x-\int_{0}^{L} q w_{0} d x \\
& =\frac{E l}{2} \int_{0}^{L}\left[\beta \dot{\theta}_{b}^{2}+(1-\beta) \dot{\theta}_{s}^{2}\right] d x-\int_{0}^{L} q w_{0} d x
\end{aligned}
$$

The above equation can be split into three parts, namely:

$U\left(\theta_{b}\right)=\frac{E l}{2} \int_{0}^{L} \beta\left[\dot{\theta}_{b}(x)\right]^{2} d x$

$$
\begin{aligned}
& U\left(\theta_{s}\right)=\frac{E l}{2} \int_{0}^{L}(1-\beta)\left[\dot{\theta}_{s}(x)\right]^{2} d x \\
& U(q)=\int_{0}^{L} q w_{0}(x) d x
\end{aligned}
$$

These equations can be viewed as representing the energy terms for the modified Euler Bernoulli beam, the shear beam and the load potential energy respectively.

\subsubsection{Modified Euler-Bernoulli Beam Element Stiffness Matrix}

The curvature for this element can be expressed in terms of nodal variables by taking the second differential of Equation (6):

$$
\begin{aligned}
& \dot{\theta}_{b}=\frac{d}{d x} \theta_{b}=\frac{d^{2}}{d x^{2}} w_{b}(x)=\sum_{i=1}^{4} \frac{d^{2}}{d x^{2}} \varphi(x) U_{i} \\
& \therefore \dot{\theta}_{b}(x)=\sum_{i=1}^{4} \ddot{\varphi}_{i}(x) u_{i}
\end{aligned}
$$

where the $\ddot{\varphi}_{i}$ is the second differential of equation of $\varphi_{i}$ and are given as

$$
\begin{aligned}
& \ddot{\varphi}_{1}=-\frac{6}{L^{2}}+\frac{12 x}{L^{3}}, \ddot{\varphi}_{2}=-\frac{4}{L}+\frac{6 x}{L^{2}}, \\
& \ddot{\varphi}_{3}=\frac{6}{L^{2}}-\frac{12 x}{L^{3}} \text { and } \ddot{\varphi}_{4}=\frac{6 x}{L^{2}}-\frac{2}{L}
\end{aligned}
$$

The energy of the modified Euler-Bernoulli beam is (Equation 25):

$$
U\left(\theta_{b}\right)=\frac{E l}{2} \int_{0}^{L} \beta\left[\dot{\theta}_{b}(x)\right]^{2} d x
$$

Substituting for $\dot{\theta}_{b}$ from Equation 28:

$U\left(\theta_{b}\right)=\frac{\beta E I}{2} \int_{x=0}^{L}\left(\sum_{i=1}^{4} \ddot{\varphi}_{i}(x) u_{i}\right)^{2} d x$

From Castigliano's first theorem, the ij stiffness coefficient $\mathrm{K}_{\mathrm{ij}}$ is given by

$$
\begin{aligned}
K_{i j} & =\frac{\partial}{\partial u_{i}} \frac{\partial}{\partial u_{j}} U\left(\theta_{b}\right) \\
i . e K_{i j} & =\frac{\partial}{\partial u_{i}} \frac{\partial}{\partial u_{j}} \frac{1}{2} \int_{x=0}^{L} \beta E I\left(\sum_{k=1}^{4} \ddot{\varphi}_{i}(x) u_{i}\right)^{2} d x \\
& =\int_{x=0}^{L} \beta E I \ddot{\varphi}_{i}(x) \ddot{\varphi}_{j}(x) d x
\end{aligned}
$$

In matrix form: 
$K_{i j}=\int_{0}^{L} \beta E I\left[\begin{array}{cccc}\ddot{\varphi}_{11} & \ddot{\varphi}_{12} & \ddot{\varphi}_{13} & \ddot{\varphi}_{14} \\ \ddot{\varphi}_{21} & \ddot{\varphi}_{22} & \ddot{\varphi}_{23} & \ddot{\varphi}_{24} \\ \ddot{\varphi}_{31} & \ddot{\varphi}_{32} & \ddot{\varphi}_{33} & \ddot{\varphi}_{34} \\ \ddot{\varphi}_{41} & \ddot{\varphi}_{42} & \ddot{\varphi}_{43} & \ddot{\varphi}_{44}\end{array}\right]$

Where $\ddot{\varphi}_{11}=\ddot{\varphi}_{1} x \ddot{\varphi}_{1}=\left(-\frac{6}{L^{2}}+\frac{12 x}{L^{3}}\right)^{2}$

$$
\ddot{\varphi}_{12}=\ddot{\varphi}_{1} \times \ddot{\varphi}_{2}=\left(-\frac{6}{L^{2}}+\frac{12 x}{L^{3}}\right)\left(-\frac{-4}{L}+\frac{6 x}{L^{2}}\right) \text {, etc. }
$$

Substituting $\ddot{\varphi}_{i j}$ into Equation (31) equations and integrating, the beam element stiffness matrix becomes:

$$
K_{b}=\frac{\beta E I}{L^{3}}\left[\begin{array}{cccc}
12 & 6 L & -12 & 6 L \\
6 L & 4 L^{2} & -6 L & 2 L^{2} \\
-12 & -6 L & 12 & -6 L \\
6 L & 2 L^{2} & -6 L & 4 L^{2}
\end{array}\right]
$$

\subsubsection{Shear Beam Element Stiffness Matrix}

The elastic strain energy for shear bending as given in Equation (26) is

$$
U\left(\theta_{s}\right)=\frac{E I}{2} \int(1-\beta)\left(\dot{\theta}_{\mathrm{s}}\right)^{2} \mathrm{dx}
$$

Similarly the curvature for this element can be expressed in terms of nodal variables thus:

$$
\begin{aligned}
& \dot{\theta}_{s}=\frac{d}{d x} \theta_{s}=\frac{d^{2}}{d x^{2}} w_{s}(x)=\sum_{i=1}^{4} \frac{d^{2}}{d x^{2}} \eta(x) u_{i} \\
& \text { i.e. } \dot{\theta}_{s}(x)=\sum_{i=1}^{4} \ddot{\eta}_{i}^{\prime}(x) u_{i}
\end{aligned}
$$

where the $\ddot{\eta}_{i}{ }^{\prime} s$ are given as

$$
\ddot{\eta}_{1}=0, \ddot{\eta}_{2}=-\frac{1}{L}, \ddot{\eta}_{3}=0 \text { and } \ddot{\eta}_{4}=\frac{1}{L}
$$

Substituting for $\dot{\theta}_{s}$ in in the shear strain energy expression (Equation 26):

$$
U\left(\theta_{s}\right)=\frac{(1-\beta) E I}{2} \int_{x=0}^{L}\left(\sum_{i=1}^{4} \ddot{\eta}_{i}(x) u_{i}\right)^{2} d x
$$

Similarly applying Castigliano's principle, the stiffness coefficient $\mathrm{K}_{\mathrm{ij}}$ is

$$
\begin{aligned}
K_{i j}=\frac{\partial}{\partial u_{i}} \frac{\partial}{\partial u_{j}} U\left(\theta_{s}\right) \\
=\frac{\partial}{\partial u_{i}} \frac{\partial}{\partial u_{j}} \frac{(1-\beta) E I}{2} \int_{x=0}^{L}\left(\sum_{k=1}^{4} \ddot{\eta}_{i}(x) u_{i}\right)^{2} d \bar{x}
\end{aligned}
$$

$$
\text { i.e. } K_{i j}=(1-\beta) E I \int_{x=0}^{L} \ddot{\eta}_{i}(x) \ddot{\eta}_{j}(x) d \bar{x}
$$

Substituting for $\ddot{\eta}_{i j}$ into Equation (35) and integrating, we have the shear beam element stiffness matrix as:

$$
\left.K_{s}=\frac{\beta E l}{L^{3}} \mid \begin{array}{llcc}
0 & 0 & 0 & 0 \\
0 & \Phi L^{2} & 0 & -\Phi L^{2} \\
0 & 0 & 0 & 0 \\
0 & -\Phi L^{2} & 0 & \Phi L^{2}
\end{array}\right]
$$

where $\Phi=\frac{1-\beta}{\beta}$

\subsubsection{The Unified Beam Element Stiffness Matrix}

The assembled unified beam element stiffness matrix, $\mathrm{K}$ is given as the summation of $\mathrm{K}_{\mathrm{b}}$ and $\mathrm{K}_{\mathrm{s}}$.

$$
\begin{aligned}
& {[K]=\left[K_{b}\right]+\left[K_{s}\right]} \\
& K=\frac{\beta E I}{L^{3}}\left[\begin{array}{llll}
12 & 6 L & -12 & 6 L \\
6 L & (4+\Phi) L^{2} & -6 L & (2-\Phi) L^{2} \\
-12 & -6 L & 12 & -6 L \\
6 L & (2-\Phi) L^{2} & -6 L & (4+\Phi) L^{2}
\end{array}\right]
\end{aligned}
$$

\subsection{Consistent Load Vector}

The consistent load vector is derived using the energy potential from the distributed loading as expressed in Equation (27):

$f_{i}=\int_{0}^{L} q(x) \sum_{i}^{4} \varphi_{i}(x) d x$

The column vector $\{f\}$ is then given by

$$
\{f\}=\int_{0}^{L} q\left[\begin{array}{llll}
\varphi_{1} & \varphi_{2} & \varphi_{3} & \varphi_{4}
\end{array}\right]^{T} d x
$$

where $\varphi_{i}$ 's are given as

$$
\begin{gathered}
\varphi_{i}=\frac{L^{3}-3 L x^{2}+2 x^{3}}{L^{3}}, \varphi_{2}=\frac{x L^{3}-2 L^{2} x^{2}+L x^{3}}{L^{3}}, \\
\varphi_{3}=\frac{3 L x^{2}-2 x^{3}}{L^{3}}, \varphi_{4}=\frac{x^{3}-L x^{2}}{L^{2}}
\end{gathered}
$$

Substituting for the $\varphi_{\mathrm{i}}$ 's in Equation (36) and integrating for a uniformly distributed load, then 
International Journal of Engineering Research and Technology. ISSN 0974-3154, Volume 13, Number 1 (2020), pp. 28-35

(C) International Research Publication House. https://dx.doi.org/10.37624/IJERT/13.1.2020.28-35

$$
\{f\}=\frac{q L}{12}\left[\begin{array}{llll}
6 & L & 6 & -L
\end{array}\right]^{T}
$$

For concentrated load, $\mathrm{P}$, at an arbitrary position on the beam, the consistent load vector is given by

$$
\begin{aligned}
& \{f\}=P \sum_{i}^{4} \varphi_{i}(x) d x \\
& \{f\}=P\left[\begin{array}{llll}
\varphi_{1} & \varphi_{2} & \varphi_{3} & \varphi_{4}
\end{array}\right]^{T}
\end{aligned}
$$

Substituting for the $\varphi_{i}$ 's in Equation (38) and putting $x=L / 2$ for midspan concentrated load, then

$$
\{f\}=P\left[\begin{array}{llll}
1 / 2 & L / 8 & 1 / 2 & -L / 8
\end{array}\right]^{T}
$$

\subsection{RESULTS AND DISCUSSION}

Consider the beams of span $\mathrm{L}$ under both a uniformly distributed load $\mathrm{q}$ and a point load $\mathrm{P}$ as shown in Figure 3.

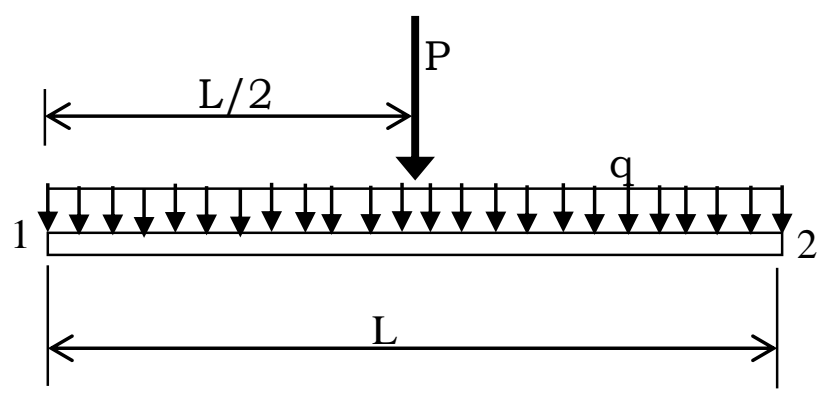

Fig.3. Loaded beam

The finite element equation of the beam element is

$$
[\mathrm{K}]\{\mathrm{u}\}=\{\mathrm{f}\}
$$

Substituting for $[\mathrm{K}]$ from Equation (37) and for $\{\mathrm{f}\}$ from Equations (40) and (42):

$$
\begin{gathered}
\frac{\beta E I}{L^{3}}\left[\begin{array}{cccc}
12 & 6 L & -12 & 6 L \\
6 L & (4+\Phi) L^{2} & -6 L & (2-\Phi) L^{2} \\
-12 & -6 L & 12 & -6 L \\
6 L & (2-\Phi) L^{2} & -6 L & (4+\Phi) L^{2}
\end{array}\right] \\
\left\{\begin{array}{c}
w_{1} \\
\theta_{1} \\
w_{2} \\
\theta_{2}
\end{array}\right\}=-\frac{q L}{12}\left\{\begin{array}{c}
6 \\
L \\
6 \\
-L
\end{array}\right\}-P\left\{\begin{array}{c}
1 / 2 \\
L / 8 \\
1 / 2 \\
-L / 8
\end{array}\right\}
\end{gathered}
$$

The assumed properties of the beam are Poisson's ratio, $\mathrm{v}=0.25$, and shear correction factor, $\mathrm{k}=5 / 6$.
For a rectangular section,

$$
\begin{aligned}
& \mathrm{I}=\frac{\mathrm{bd}^{3}}{12}, \mathrm{~A}=\mathrm{bd}, \mathrm{k}=\frac{5}{6} \text {.and } \mathrm{G}=\frac{\mathrm{E}}{2(1+v)}=\frac{\mathrm{E}}{2.5} \\
& \therefore \Phi=\frac{12 E I}{L^{2} k A G}=3\left(\frac{d}{L}\right)^{2}
\end{aligned}
$$

Solutions for various boundary conditions are obtained as follows:

\subsection{Pinned - Pinned Ends}

The boundary conditions are $\mathrm{w}_{1}=\mathrm{w}_{2}=0$

The maximum deflection $\mathrm{w}_{\mathrm{c}}$ at mid-span is obtained by inserting a node at $\mathrm{L} / 2$. This gives

$$
w_{c}=-\frac{q L^{4}}{384 E I}(5+\Phi)-\frac{P L^{3}}{192 E I}(4+\Phi)
$$

For $\Phi=0$ (Euler-Bernoulli beam):

$$
w_{b}=-\frac{5 q L^{4}}{384 E I}-\frac{P L^{3}}{48 E I}
$$

The ratio of the maximum deflection of the Timoshenko beam to that of the classical beam, $\mathrm{W}_{\mathrm{c}} / \mathrm{W}_{\mathrm{b}}$, is calculated as:

(i) For point load $\mathrm{P}=0, \Phi=3\left(\frac{d}{L}\right)^{2}$

$$
C_{w q}=\frac{w_{c}}{w_{b}}=1+0.6\left(\frac{d}{L}\right)^{2}
$$

(ii) For udl $\mathrm{q}=0, \Phi=3\left(\frac{d}{L}\right)^{2}$

$$
C_{w P}=\frac{w_{c}}{w_{b}}=1+0.75\left(\frac{d}{L}\right)^{2}
$$

\subsection{Fixed-Free Ends}

The boundary conditions are $\mathrm{w}_{1}=\theta_{1}=0$

Deflection at the free end with the point load at the free end is

$$
w_{2}=-\frac{q L^{4}}{24 E I}(3+2 \Phi)-\frac{P L^{3}}{12 E I}(4+\Phi)
$$

For $\Phi=0$ (Euler-Bernoulli beam):

$$
w_{b}=-\frac{q L^{4}}{8 E I}-\frac{P L^{3}}{3 E I}
$$


International Journal of Engineering Research and Technology. ISSN 0974-3154, Volume 13, Number 1 (2020), pp. 28-35

(C) International Research Publication House. https://dx.doi.org/10.37624/IJERT/13.1.2020.28-35

(i) For point load $\mathrm{P}=0, \Phi=3\left(\frac{d}{L}\right)^{2}$

$$
C_{w q}=\frac{w_{2}}{w_{b}}=1+2\left(\frac{d}{L}\right)^{2}
$$

(ii) For udl $\mathrm{q}=0$,

$$
\Phi=3\left(\frac{d}{L}\right)^{2}
$$

$$
C_{w P}=\frac{w_{2}}{w_{b}}=1+0.75\left(\frac{d}{L}\right)^{2}
$$

\subsection{Fixed-Fixed Ends}

The boundary conditions are $\mathrm{w}_{1}=\mathrm{w}_{2}=\theta_{1}=\theta_{2}=0$

The maximum deflection at midspan, $\mathrm{w}_{\mathrm{c}}$, is

$w_{c}=-\frac{q L^{4}}{384 E I}(1+\Phi)-\frac{P L^{3}}{192 E I}(1+\Phi)$

For $\Phi=0$ (Euler-Bernoulli beam):

$w_{b}=-\frac{q L^{4}}{384 E I}-\frac{P L^{3}}{192 E I}$

(i) For point load $\mathrm{P}=0, \Phi=3\left(\frac{d}{L}\right)^{2}$

$$
C_{w q}=\frac{w_{c}}{w_{b}}=1+3\left(\frac{d}{L}\right)^{2}
$$

(ii) For udl $\mathrm{q}=0, \Phi=3\left(\frac{d}{L}\right)^{2}$

$$
C_{w P}=\frac{w_{c}}{w_{b}}=1+3\left(\frac{d}{L}\right)^{2}
$$

The summary of the derived expressions for maximum deflection for various support conditions is shown in Table 1.

Table 1:Derived Expressions for Maximum deflection for Various Support Conditions of the Timoshenko Beam

\begin{tabular}{|l|l|l|}
\hline \multirow{2}{*}{$\begin{array}{l}\text { Support } \\
\text { Condition }\end{array}$} & \multicolumn{1}{|l|}{ Maximum Deflection } \\
\cline { 2 - 3 } & TBFE Solution & $\begin{array}{c}\text { EBT (Classical) } \\
\text { Solution } \\
(\Phi=0)\end{array}$ \\
\hline $\begin{array}{l}\text { Pinned- } \\
\text { Pinned }\end{array}$ & $-\frac{q L^{4}}{384 E I}(5+\Phi)-\frac{P L^{3}}{192 E I}(4+\Phi)$ & $-\frac{5 q L^{4}}{384 E I}-\frac{P L^{3}}{48 E I}$ \\
\hline Fixed-Free & $-\frac{q L^{4}}{24 E I}(3+2 \Phi)-\frac{P L^{3}}{12 E I}(4+\Phi)$ & $-\frac{q L^{4}}{8 E I}-\frac{P L^{3}}{3 E I}$ \\
\hline $\begin{array}{l}\text { Fixed- } \\
\text { Fixed }\end{array}$ & $-\frac{q L^{4}}{384 E I}(1+\Phi)-\frac{P L^{3}}{192 E I}(1+\Phi)$ & $-\frac{q L^{4}}{384 E I}-\frac{P L^{3}}{192 E I}$ \\
\hline
\end{tabular}

$\underline{\text { Legend }}$

TBFE - Timoshenko Beam Finite Element

EBT - Euler-Bernoulli Beam Theory

Table 2 shows the relationship between the span-to-depth $\left(\frac{L}{d}\right)$ ratio and the $\frac{w_{c}}{w_{b}}$ ratio

Table 2:Relationship Between Span/depth $\left(\frac{L}{d}\right)$ Ratio and $\frac{w_{c}}{w_{b}}$ Ratio

\begin{tabular}{|c|c|c|c|c|c|c|}
\hline$\left(\frac{L}{d}\right)$ Ratio & \multicolumn{7}{|c|}{$C_{w}=\frac{w_{c}}{w_{b}}$} \\
& \multicolumn{7}{|c|}{} \\
\cline { 2 - 7 } & \multicolumn{7}{|c|}{ Pinned - Pinned } & \multicolumn{3}{c|}{ Fixed - Free } & \multicolumn{1}{c|}{ Fixed - Fixed } \\
\cline { 2 - 7 } & $\mathbf{P}=\mathbf{0}$ & $\mathbf{q}=\mathbf{0}$ & $\mathbf{P}=\mathbf{0}$ & $\mathbf{q}=\mathbf{0}$ & $\mathbf{P}=\mathbf{0}$ & $\mathbf{q}=\mathbf{0}$ \\
\hline 100 & 1.000 & 1.000 & 1.000 & 1.000 & 1.000 & 1.000 \\
\hline 20 & 1.002 & 1.002 & 1.005 & 1.002 & 1.008 & 1.008 \\
\hline 10 & 1.006 & 1.008 & 1.020 & 1.008 & 1.030 & 1.030 \\
\hline 5 & 1.024 & 1.030 & 1.080 & 1.030 & 1.120 & 1.120 \\
\hline 4 & 1.038 & 1.047 & 1.125 & 1.047 & 1.188 & 1.188 \\
\hline 2 & 1.150 & 1.188 & 1.509 & 1.188 & 1.750 & 1.750 \\
\hline 1 & 1.600 & 1.750 & 3.000 & 1.750 & 4.000 & 4.000 \\
\hline
\end{tabular}

Legend

$w_{c}$ - Maximum deflection from TBFE Solution

$w_{b}$ - Maximum deflection from EBT (classical) Solution

$C_{w}=\frac{w_{c}}{w_{b}}=$ ratio of the maximum deflection of the Timoshenko beam to that of the classical beam

Table 1 displays the derived explicit expressions for maximum deflection of beams for various support conditions using the proposed unified finite element model.

Table 2 shows the relationship between the span-to-depth $\left(\frac{L}{d}\right)$ ratio and the $\frac{w_{c}}{w_{b}}$ ratio for various support conditions. $\frac{w_{c}}{w_{b}}$ is the ratio of the maximum deflection of the Timoshenko beam to that of the classical beam. Table 2 shows that the effect of shear deformation on the deflection of beams in all support conditions becomes significant for span-to-depth ratios less than 10 . For $\mathrm{L} / \mathrm{d}=5$, shear deformation accounts for up to $2.4 \%$ increase in deflection values of a beam with pinned ends and a central point load; the figure is even higher for the other support conditions. 


\subsection{CONCLUSIONS}

A unified finite element model for deflection analysis of Timoshenko beams has been developed. The developed element is free from shear locking, the bending and shear curvatures having been successfully decoupled using energy separation principle. The results obtained using this model are seen to be in very good agreement with classical beam theories for combined bending and shear deformation. Also, excellent results are obtained with one-element mesh in contrast to other finite element solutions by Reddy (2006). Explicit expressions for deflection of beams with various support conditions, taking into account both bending and shear deformation, have been derived using the finite element model. The unified finite element model is shown to model shearing deformation extremely closely.

It is concluded that the effect of shear deformation on deflection of beams is significant for span-to-depth ratios less than 10 and should therefore be accounted for in the design of such beams.

\section{REFERENCES}

[1] Antes, H. (2003): "Fundamental Solution and Integral Equations for Timoshenko Beams", Journal of Computers \& Structures, Vol. 81, pp. 383-396.

[2] Carpenter, N., Belytschko, T., and Stolarski, H. (1986): "Locking and Shearscaling Factors in C0 Bending Elements," Computer and Structure, 22, 39.

[3] Cleghorn, W. L. and Tabarrok B. (1992): "Finite Element Formulation of a Tapered Timoshenko Beam for Free Lateral Vibration Analysis", Journal of Sound and Vibration, Vol. 152, No. 3, pp. 461470.

[4] Edem, I. B. (2006): "The Exact Two-Node Timoshenko Beam Finite Element Using Analytical Bending and Shear Rotation Interdependent Shape Functions", International Journal for Computational Methods in Engineering Science and Mechanics, Vol. 7, pp. 425-431.

[5] Jang, J. and Suh-Yuh, Y. (2000): "Least-Squares Finite Element Approximations to the Timoshenko Beam Problem", Applied Mathematics and Computation, Vol. 115, pp. 63-75.

[6] Levinson, M. (1988): “A new Rectangular Beam Theory", Journal of Sound and Vibration, Vol. 74, pp. 81-87.

[7] Onyia, M.E. and Rowland-Lato, E.O.(2018): "Determination of the Critical Buckling Load of Shear Deformable Unified Beam", International Journal of Engineering and Technology (IJET), Vol. 10 , Issue 3.

[8] Prathap, G. (1982): "Reduced Integration and the Shear Flexible Beam Element", International Journal of Numerical. Methods, Vol. 18, 195
[9] Prathap, G. (1987): "Field-consistency and Violent Stress Oscillations in the Finite Element Method", International Journal of Numerical. Methods, Vol. 24, 2017.

[10] Reddy, J.N. (1993):“An Introduction to the Finite Element Method”, 2nd edition, McGraw-Hill, New York.

[11] Reddy, J.N. (1997):“'On Locking-Free ShearDeformable Beam Finite Elements", Computational Methods of Applied Mechanics in Engineering, Vol.149, pp. 113-132

[12] Reddy, J.N. and Wang, C. M. (1997):“Relationships Between Bending Solutions of Classical and Shear Deformation Beam Theories", International Journal of Solids and Structures, Vol. 34, pp. 3373-3384.

[13] Reddy, J.N., Wang, C.M., Lim, G.T. and Ng, K.H. (2001):"Bending Solutions of Levinson Beams and Plates in Terms of the Classical Theories", International Journal of Solids and Structures, Vol. 38, pp. 4701-4720

[14] Shimpi, R.P. and Ainapure, A.V. (2001): “A Beam Finite Element based on Layerwise Trigonometric Shear Deformation Theory", Composite Structures, Vol. 53, pp. 153-162. 